\section{Cracking the Genome}

\author{
by Kevin Davies
}

Free Press, 288 pp, $\$ 25.00$

ISBN: 0743204794; 2001

Reviewed by Peter P. Tolias

Center for Applied Genomics,

Public Health Research Institute and UMDNJNew Jersey Medical School

Newank, New Jersey, USA

In less than $\mathbf{5 0}$ years, the field of genetics has evolved rapidly, from solving the structure of DNA to obtaining our first glimpse of the nucleotide sequence of the human genome. Cracking the Genome chronicles the major scientific milestones and drama that led to what author Kevin Davies rightly refers to as "the greatest scientific discovery of our time." The book also addresses how sequencing the human genome has changed the manner and scope by which biology is studied and commercialized, and discusses the possible implications for the future of society. As these important historical facts and issues are-to my knowledge-yet to be covered in depth in any other single publication, this book definitely deserves a read.

Kevin Davies is the founder and a former editor of Nature Genetics, and currently the Editor-in-Chief of Cell Press. In Cracking the Genome, he uses his scientific and literary skills in an ambitious attempt to target both a lay and scientific audience in describing the inside story of how we came to sequence the human genome and the significance of this endeavor. The book begins with a historical survey of the first hundred years of genetic research, outlining key discoveries by pioneering scientists that were instrumental in leading Watson and Crick to decipher the structure of the DNA double helix by 1953 . Davies then quickly moves us through the molecular era to the genomic era, marked by the launch of the Human Genome Project by the Department of Energy.

Readers are then presented with a layman's course in genetics. Anyone with a bachelor's degree in biology may want to skip ahead. Those who don't learn about DNA structure, replication, repair and transcription, and are coached on RNA processing. transport and translation until they arrive at a detailed discussion of genetic variation, and how mistakes in any one of these processes can lead to disease.

The main characters of the plot do not emerge until chapters 3 and 4 where we are presented with complete biographical sketches of Craig Venter and Francis Collins. We learn about Venter's youth as a surfer, his transformation in Vietnam, his subsequent education and early scientific career and the seminal contributions he made as a maverick sequencer of expressed sequence tags at the NIH (National Institutes of Health). Davies also presents Venter's disputes with and subsequent departure from the $\mathrm{NIH}$, and his growing fame and wealth resulting from his involvement in the founding of The Institute for Genomic Research (TIGR), Human Genome Sciences and Celera. The rise of Francis Collins to national prominence is laid out from his days mapping and cloning disease genes, to

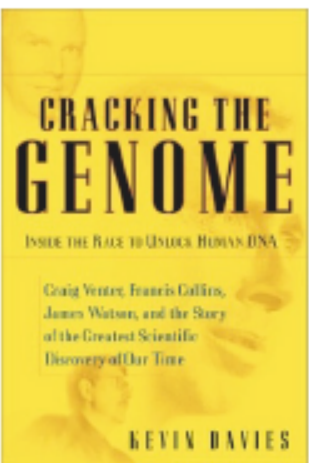

experience as a leading editor to solicit first-hand interviews with the key scientists instrumental to this global effort. However, with the exception of the effective use of metaphors as chapter titles, I felt shortchanged by the dry writing style-it lacked the character and passion such a monumental human accomplishment should elicit. This shortcoming may reflect the author's emphasis on a detailed explanation of genetics for a lay audience. The end result is an ambitious book that targets both a lay audience, which is carefully tutored on many aspects of genetics, as well as research scientists, who must endure this spoon feeding until they reach the facts, history and drama of the sequencing of the human his succeeding James Watson as leader of the Human Genome Project and director of the National Center for Human Genome Research.

Davies proceeds to tutor readers on techniques developed to map human disease genes, and how the public consortium applied these techniques to sequence model organisms (yeast and worms) and finally the human genome. He contrasts this with the 'shotgun sequencing' and computer assembly strategy successfully pioneered by Venter at TIGR for sequencing bacteria, and later adapted at Celera for sequencing the Drosophlla and human genomes. The value of studying genetic variation in geographically or culturally isolated populations is discussed at length.

The rest of the book is laid out in a scrambled fashion. Davies backtracks to detail the creation of Celera and takes us through the nasty exchanges between the private and public human genome sequencing efforts and the ensuing media frenzy. He then skips to what the genome has revealed about our evolution as a species, flips back to the drama of the sequencing race, then discusses the implications of this effort to future research and the potential consequences on humanity. The book ends with the public announcement by Venter, Collins and President Clinton that the race is over and our first draft is at hand.

My overall impression of this book is a positive one and I commend Davies for a good try. The details and perspective provided in this history of the human genome project clearly result from the author's ability to combine his expertise in genetics and genome. This difficult endeavor may have been better served by two books. I also had difficulty with the overall disorganization of the chapters and their lack of continuity. Finally, I found the title misleading-the word "cracking" could be understood by a lay audience as the decoding and functonal understanding of the genome. Scientists, however, know that the code of the genome is far from being cracked and that this effort will fuel research for decades to come.

\section{Dark Remedy: The Impact of Thalidomide and Its Revival as a Vital Medicine}

\author{
by Rock Brynner \& \\ Trent D. Stephens \\ Perseus Books, 208 pp, $\$ 26.00$ \\ ISBN: 0738204048; 2001
}

\section{REVIEWED BY KeNNETH C. ANDERSON \\ Dana-Farber Cancer Institute \\ Boston, Massach usetts}

Dark Remedy: The Impact of Thalidomide and Its Revival as a Vital Medicine is a historical account of the development and clinical use of thalidomide, which const 1 tuted one of the most devastating from the personal perspective of Trent Stephens, whose research on limb development helped to delineate thalidotragedies of modern medicine. It is told 